\title{
Taking the elephant out of the room and into the corridor: can urban corridors work?
}

\author{
Tempe S. F. Adams, Michael J. Chase \\ Tracey L. Rogers and Keith E. A. Leggett
}

\begin{abstract}
Transfrontier wildlife corridors can be successful conservation tools, connecting protected areas and reducing the impact of habitat fragmentation on mobile species. Urban wildlife corridors have been proposed as a potential mitigation tool to facilitate the passage of elephants through towns without causing conflict with urban communities. However, because such corridors are typically narrow and close to human development, wildlife (particularly large mammals) may be less likely to use them. We used remote-sensor camera traps and global positioning system collars to identify the movement patterns of African elephants Loxondonta africana through narrow, urban corridors in Botswana. The corridors were in three types of human-dominated land-use designations with varying levels of human activity: agricultural, industrial and openspace recreational land. We found that elephants used the corridors within all three land-use designations and we identified, using a model selection approach, that season, time of day and rainfall were important factors in determining the presence of elephants in the corridors. Elephants moved more slowly through the narrow corridors compared with their movement patterns through broader, wide-ranging corridors. Our results indicate that urban wildlife corridors are useful for facilitating elephants to pass through urban areas.
\end{abstract}

Keywords Camera traps, conservation, human-elephant coexistence, land management, urban wildlife corridors

To view supplementary material for this article, please visit http://dx.doi.org/10.1017/So030605315001246

Tempe S. F. Adams ${ }^{*}$ (Corresponding author) and Keith E. A. Leggett Fowlers Gap Arid Zone Research Station, Centre of Ecosystem Science, School of Biological Earth and Environmental Sciences, University of New South Wales, Australia. E-mail tempe@student.unsw.edu.au

Michael J. Chase Elephants Without Borders, Kasane, Botswana

Tracey L. Rogers Evolution \& Ecology Research Centre, School of Biological Earth and Environmental Sciences, University of New South Wales, Australia

${ }^{*}$ Also at: Elephants Without Borders, Kasane, Botswana, and Evolution \& Ecology Research Centre, School of Biological Earth and Environmental Sciences, University of New South Wales, Australia

Received 5 August 2015. Revision requested 23 September 2015. Accepted 28 October 2015. First published online 6 May 2016.

\section{Introduction}

T U uman population increase has resulted in increased 1 fragmentation of wildlife habitat (Johnsingh \& Williams, 1999; Osborn \& Parker, 2003) and consequently the formation of isolated protected areas (the so-called island effect). The lack of connectivity between protected areas can have a negative impact on wildlife, particularly on large, wide-ranging species (Hilty \& Merenlender, 2004; Kuykendall \& Keller, 2011). Wildlife corridors that connect favoured habitats (Caro et al., 2009; Mangewa et al., 2009) are potentially a solution to the problem, although their value has been debated (Hilty \& Merenlender, 2004). To date, research has concentrated on the value of transfrontier connections through humanmodified landscapes, linking protected wildlife areas (Osborn \& Parker, 2003; Douglas-Hamilton et al., 2005; Mangewa et al., 2009), and creating vital links between protected areas and resources (Gilbert et al., 1998; Hilty \& Merenlender, 2004; Caro et al., 2009; Mangewa et al., 2009). However, there is a need for a better understanding of wildlife movements at a smaller spatial scale, through urban settlements in or adjacent to wildlife protected areas (Carter et al., 2012), where the passage of wildlife is facilitated by narrow (5-400 $\mathrm{m}$ ) pathways. Human encroachment on and around wildlife pathways is an important driver of human-wildlife conflict (Carter et al., 2012; Songhurst \& Coulson, 2014), which inevitably occurs when people and wildlife come into direct contact (Sitati et al., 2003; Graham et al., 2009; Carter et al., 2012; Runge et al., 2014; Songhurst et al., 2015). However, securing space for wildlife to pass unimpeded through community areas could facilitate coexistence and potentially offer a long-term solution to conflict. The small-scale movement of wildlife through human settlements is relatively unexplored (Carter et al., 2012) but is increasingly important as human populations increase and people come into closer contact with wildlife.

The design and implementation of a wildlife corridor in an urban setting involves particular constraints. The use of corridors by wildlife depends on the availability of appropriate habitat cover that provides browsing material and a means of avoiding predators (Newmark, 1993); for example, the eland Taurotragus oryx, the greater kudu Tragelaphus strepsiceros and the lesser kudu Tragelaphus imberbis are sensitive to human-altered landscapes that lack resources for predator avoidance, and therefore thick habitat coverage is critical to their use of a corridor (Newmark, 1993). The 
success of a corridor may also depend on the terrain, the human population density (Roever et al., 2013) and the location of roads (Kuykendall \& Keller, 2011), as well as the proximity, size and land use of human settlements (Songhurst et al., 2015) People may be perceived as a threat and may also compete directly with wildlife for resources (Head et al., 2012; Songhurst et al., 2015).

We do not know how species will use human-shared habitats and whether or not coexistence in compact areas is a viable conservation option, especially for large mammals (Carter et al., 2012; LaPoint et al., 2013). There are concerns about the impact of habitat fragmentation on large mammals and how they operate at broad spatial scales (LaPoint et al., 2013; Roever et al., 2013). We do not know if they can function alongside people at small spatial scales (Patterson, 1984; Wright \& Coleman, 1993; Carter et al., 2012), as they require a large home range for food resources (Kelt \& Van Vuren, 2001; Jetz et al., 2004; Tucker et al., 2014). For migratory species, understanding their movement patterns is vital for their conservation; to understand the challenges that will be faced in securing their future, one must first understand where they go (Runge et al., 2014). The African elephant Loxodonta africana is an ideal model species as it is large, wide ranging and terrestrial, and often co-occurs with other species of conservation concern (Roever et al., 2013). Elephants are known to use wildlife corridors and pathways through human-modified landscapes when moving between protected areas or to access resources (Douglas-Hamilton et al., 2005; Graham et al., 2009; Songhurst et al., 2015). However, we have limited knowledge of their use of smaller corridors that pass directly through human settlements (Head et al., 2012).

Botswana is home to the largest population of African elephants (c. 130,000; Chase et al., 2015) as well as a rapidly increasing human population $(20.5 \%$ increase during $2001-$ 2011; Census Office, 2014). Human settlements within the elephant's range are located close to resources such as rivers and nutrient-rich soils, which are used by both wildlife and people. This overlap poses a challenge in managing the increasing human population (Chase, 2007), and requires the establishment of better management and land-use practices to facilitate coexistence between people and wildlife (Songhurst et al., 2015).

Our objective was to assess whether the African elephant would use narrow urban wildlife corridors. We used a series of remote-sensor camera traps, and data from global positioning system (GPS) collars, to investigate corridor use in three human-dominated land-use types over 2 years. We predicted that elephants would use the corridors in temporal and spatial patterns that minimized their interaction with people.

\section{Study area}

The study was conducted in the townships of Kasane and Kazungula, which together comprise the largest human settlement in the $22,560 \mathrm{~km}^{2}$ Chobe District, in northeastern Botswana (Fig. 1); $70 \%$ of the Chobe District is formally protected (52\% in Chobe National Park and $18 \%$ as forest reserve).

Chobe District is bordered to the north by Namibia and Zambia, and to the east by Zimbabwe. Kasane and Kazungula lie between the Chobe/Zambezi River and the protected areas of Chobe National Park and Chobe Forest Reserve. The human population of Chobe District increased by $27.9 \%$ during 2001-2011 (Census Office, 2014) and is set to continue increasing. Kasane and Kazungula are the two largest human settlements in the northern region of the elephant's range, with a combined population of c. 13,000 people (Census Office, 2014), and a density of 301 people per $\mathrm{km}^{2}$. There is no standardized definition of what constitutes an urban area (Brenner \& Schmid, 2014) but Kasane and Kazungula are categorized as urban based on their increasing populations and the availability of amenities and services (Joos-Vandewalle, 2015).

The elephant population in Chobe District is estimated to be c. 32,000 (Chase et al., 2015), with c. 17,000 in Chobe National Park. Elephants pass through Kasane and Kasungula en route from the Park and forestry reserves to the river. Both communities are located on the banks of the Chobe River, which is a perennial river system that joins the Kwando-Linyanti and Zambezi river systems.

Northern Botswana is semi-arid with a sub-tropical climate and four seasons: the cold dry season (May-July), the hot dry season (August-October), the wet season (November-March) and the post wet season (April), when the rains have stopped but the majority of natural pans away from permanent water sources are still full (Clark, 2013). The rainfall data used in this study were obtained from the Government of Botswana Bureau of Meteorology, Kasane Station (Government of Botswana, 2014).

\section{Methods}

\section{Monitoring}

We monitored seven corridors within three designated land uses over a distance of c. $5 \mathrm{~km}$ (Ministry of Lands, Housing and Environment, 2000): two are in open space and conservation areas (A), three in industrial areas (B) and two in agricultural areas (C; Fig. 1). The agricultural corridors (C) are designated (i.e. they are acknowledged by the local council on planning maps as areas of wildlife use; Ministry of Lands, Housing and Environment, 2000), whereas the corridors in land uses $\mathrm{A}$ and $\mathrm{B}$ are non-designated (i.e. they are not officially planned or acknowledged).

All of the corridors have similar geographical attributes, with elephants entering from the forestry reserve and passing through the corridors to access the Chobe 


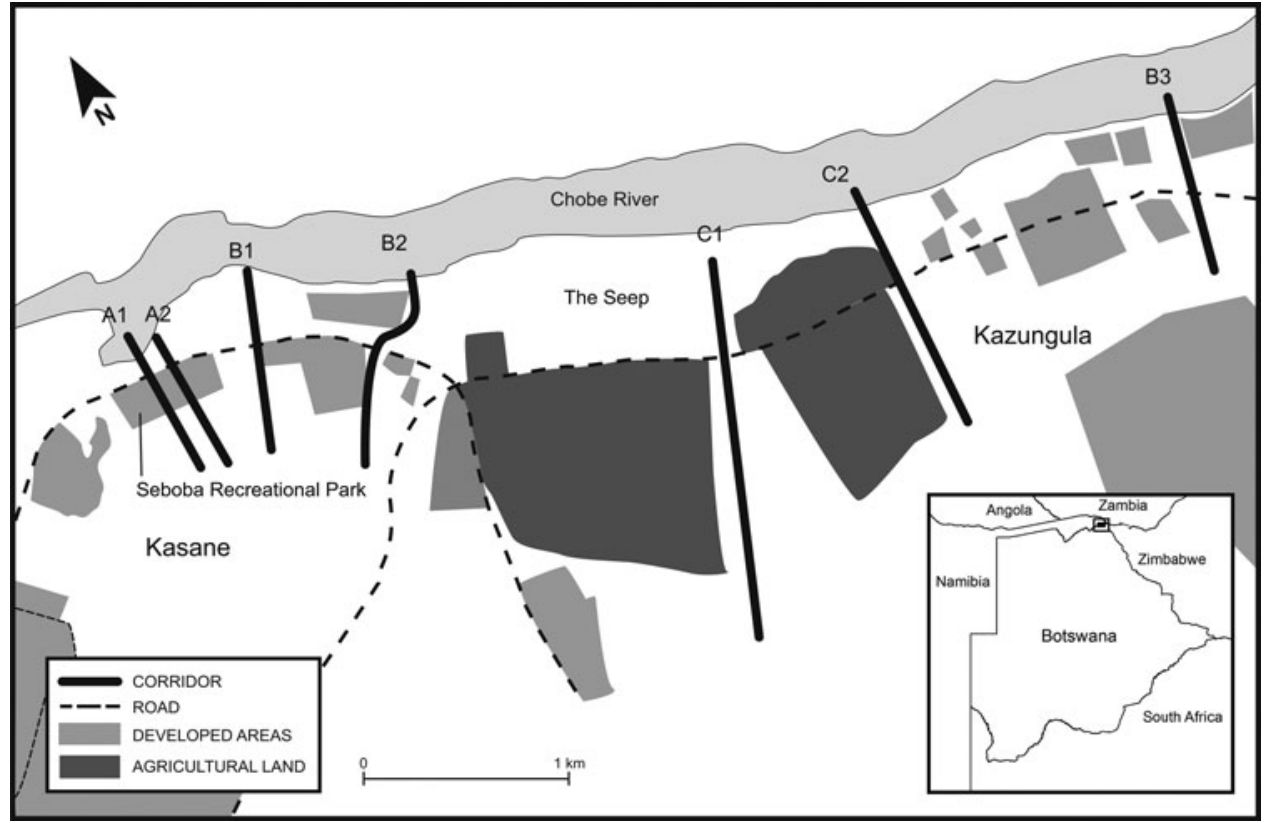

FIG.1 Wildlife corridors through the Kasane and Kazungula communities in Chobe District, north-eastern Botswana. Corridors A1 and A2 pass through open space and conservation areas; $\mathrm{B}_{1}, \mathrm{~B}_{2}$ and $\mathrm{B}_{3}$ pass through industrial areas; $\mathrm{C}_{1}$ and $\mathrm{C}_{2}$ pass through agricultural areas.
River (Fig. 1). The corridors through the open space and conservation area are $80 \mathrm{~m}$ apart and located north of the main road. Each runs from outside Kasane to the Seboba Recreational Park on the Chobe River, in close proximity to a number of local businesses and a commercial development site. There is a relatively high level of human activity in the Seboba Recreational Park, which is used for fishing, religious ceremonies and other cultural activities. There is a fence along the main road, in which two gaps have been opened for corridors A1 (length c. $750 \mathrm{~m}$, minimum width c. $3 \mathrm{~m}$; Supplementary Plate $\mathrm{S}_{1}$ ) and A2 (length c. $750 \mathrm{~m}$ minimum width c. $3 \mathrm{~m}$ ), and this is the narrowest part of the corridors. We set one camera on each of these corridors to record any movement of elephants through the gaps in the fence.

The agricultural corridors are located between Kasane and Kazungula, in an area known as the Seep (Fig. 1). The Kazungula highway runs directly through the area, with the Chobe River flowing adjacent to the road. The corridors $\mathrm{C}_{1}$ (length c. 1,700 m, minimum width c. $250 \mathrm{~m}$ ) and C2 (length c. $1,700 \mathrm{~m}$, minimum width c. $250 \mathrm{~m}$ ) run alongside the two largest commercial farms in the Kasane area. The end point of both corridors is a natural hot spring (the Seep) that opens onto the river, which is a popular recreational site at weekends.

Unlike in the other two land-use areas, the three corridors monitored in industrial areas (B1: length c. $900 \mathrm{~m}$, minimum width $4 \mathrm{~m}$; B2: length c. $900 \mathrm{~m}$, minimum width $6 \mathrm{~m}$; $\mathrm{B}_{3}$ : length c. $1,000 \mathrm{~m}$, minimum width $50 \mathrm{~m}$ ) are not located alongside one another (Fig. 1). B1 is a narrow, fenced corridor between Seboba Recreational Park and a jail farm; $\mathrm{B} 2$ is a narrow, fenced passage between two government offices, which continues alongside a private lodge and camp ground; and $\mathrm{B}_{3}$ passes between a lodge and residences (Fig. 1).

To monitor the presence of elephants in the corridors we installed one Bushnell Trophy Cam Brown HD (119437c) camera trap (Bushnell Corporation, Overland Park, USA) in each corridor (Carter et al., 2012; LaPoint et al., 2013). Cameras were attached to trees or posts, c. 1.5-1.8 m above the ground and facing paths used by wildlife, and remained in the same position throughout the study. Photographs were downloaded from the memory cards each week. Four of the cameras ( $A_{1}, A_{2}, C_{1}$ and $C_{2}$ ) were deployed in November 2012 for 18 months, two (B1 and $\mathrm{B}_{3}$ ) in February 2013 for 14 months, and one (B2) in April 2013 for 12 months. Cameras operated continuously for 24 hours per day and recorded photographs at $3 \mathrm{~s}$ intervals when triggered by movement, until the detected target was out of range (c. $20 \mathrm{~m}$ from the camera). For each photograph we recorded the time, date and number of species captured.

The NGO Elephants Without Borders fitted a mature adult cow $(\mathrm{CH} 67)$ in the Kasane-Kazungula region and a mature bull elephant $(\mathrm{CH} \mathrm{60})$ on the Chobe riverfront within Chobe National Park with GPS satellite collars (African Wildlife Tracking, Pretoria, South Africa). The collars were set to record the location of the elephants every hour. We used data recorded during 1 October 2012-30 October 2013, which coincides with the period of camera trapping.

\section{Statistical analysis}

We recorded a single count of presence (1) or absence (o) for each day in each corridor, depending on whether or not 
TABLE 1 The summary statistics for each of the generalized linear mixed models in which daily presence/absence of elephants Loxodonta africana was the response variable, with model parameters, corrected Akaike information criterion (AICc), $\triangle \mathrm{AIC}$, AIC weight, and evidence ratio. Parentheses indicate random factors.

\begin{tabular}{lllrrr}
\hline Model no. & Model parameters & AICc & \multicolumn{1}{c}{$\Delta$ AIC } & AIC weight & Evidence ratio \\
\hline 1 & Season + (Rainfall) + (Corridor) & $2,854.40$ & 0.00 & 1.00 & $1.00 \mathrm{e}+00$ \\
2 & Season + Width + (Year) + (Corridor) & $2,900.60$ & 46.20 & 0.00 & $1.07 \mathrm{e}+10$ \\
3 & Season + Day of the week + (Year) + (Corridor) & $2,918.34$ & 63.94 & 0.00 & $7.67 \mathrm{e}+13$ \\
4 & Season + Width + (Corridor) & $2,920.08$ & 65.68 & 0.00 & $1.83 \mathrm{e}+14$ \\
5 & Season + Width + Day of the week + (Corridor) & $2,928.76$ & 74.37 & 0.00 & $1.40 \mathrm{e}+16$ \\
6 & Land designation + Season + (Corridor) & $2,934.05$ & 79.65 & 0.00 & $1.97 \mathrm{e}+17$ \\
7 & Land designation + (Rainfall) + (Corridor) & $2,956.89$ & 102.49 & 0.00 & $1.79 \mathrm{e}+22$ \\
\hline
\end{tabular}

TABLE 2 The summary statistics for each of the generalized linear mixed models in which hourly presence/absence of elephants was the response variable, with model parameters, corrected Akaike information criterion (AICc), $\triangle \mathrm{AIC}$, AIC weight, and evidence ratio. Parentheses indicate random factors.

\begin{tabular}{llrrrr}
\hline Model no. & Model parameters & AICc & \multicolumn{1}{c}{$\Delta$ AIC } & AIC weight & Evidence ratio \\
\hline 1 & Hour + Land designation + Season + (Corridor) & $1,352.52$ & 0.00 & 1.00 & $1.00 \mathrm{e}+00$ \\
2 & Season + Width + (Traffic) + (Corridor) & $1,368.99$ & 16.47 & 0.00 & $3.77 \mathrm{e}+03$ \\
3 & Season + (Traffic) + (Corridor) & $1,379.43$ & 26.91 & 0.00 & $6.97 \mathrm{e}+05$ \\
4 & Land designation + Season +(Traffic) + (Corridor) & $1,381.33$ & 28.81 & 0.00 & $1.80 \mathrm{e}+06$ \\
5 & Land designation + (Traffic) + (Corridor) & $1,450.86$ & 98.34 & 0.00 & $2.26 \mathrm{e}+21$ \\
6 & Season + (Corridor) & $1,660.21$ & 307.69 & 0.00 & $6.53 \mathrm{e}+66$ \\
7 & Land designation + Season + (Traffic) + (Corridor) & $1,661.91$ & 309.39 & 0.00 & $1.52 \mathrm{e}+67$ \\
\hline
\end{tabular}

elephants were photographed. We calculated zero inflation and overdispersion in the data, and selected the appropriate family function. To determine if and how elephants used the urban corridors we created seven binomial generalized linear mixed models in $R$ v. 3.1.2 (R Development Core Team, 2010), using the Ime4, MASS and NLME packages, to investigate which factors influenced elephants' daily usage of the corridors (Underwood, 1997). Elephant presence in a corridor was tested as a function of land-use designation, corridor, day, corridor width, season, rainfall and year. Corridor, rainfall and year were random factors (Underwood, 1997). Model selection was based on Akaike's information criterion (AIC; Burnham et al., 2011); the lower the AIC score, the better the model. Summary function was used for the result output. Significance was determined for all analyses at $\mathrm{P}<0.05$.

To identify the factors that influenced elephants' finer-scale movements in the corridors we examined data on an hourly time scale. Presence or absence was recorded in 2-hourly time intervals for each month. We used binomial generalized linear mixed models in which the fixed factors were hour (2-hourly interval), season, land-use designation, and width of corridor; corridor and traffic were random factors (Underwood, 1997). Traffic was measured by counting all vehicles along the highway during a randomly selected 10-minute period every hour. The 10-minute counts were averaged for 2-hourly blocks and used as an indicator of road usage in the area.

\section{Results}

We recorded a total of 2,619 images of elephants across the seven corridors over a 516-day period during 1 November 2012-30 April 2014. Both bulls and breeding herds with young calves were recorded. Elephants' daily and hourly use of the corridors followed a temporal pattern on hourly, daily, seasonal and annual scales (Tables $1 \& 2$ ). Other species were also detected in the corridors. Camera B2 (Fig. 1) recorded the highest species diversity, with 19 species, ranging from small carnivores, such as civets Civettictis civetta, to buffalo Syncerus caffer.

Daily corridor usage The presence of elephants in the corridors was influenced significantly by season and rainfall (Table 1, Fig. 2, Supplementary Table S1). The highest usage was in August, with a mean of $13 \pm \mathrm{SE}_{2}$ detections per day, followed by April, with $12 \pm \mathrm{SE} 1$. Activity increased significantly in the post wet $(z=8.528$, $\mathrm{SE}=0.18, \quad \mathrm{P}<0.001), \quad$ hot $\operatorname{dry} \quad(z=6.53, \quad \mathrm{SE}=0.15$, $\mathrm{P}<0.001)$ and wet $(z=1.67, \mathrm{SE}=0.13, \mathrm{P}<0.05)$ seasons in each of the land-use designations (Fig. 2). There was a negative relationship between rainfall and elephant presence.

Hourly usage Elephants were active in each of the corridors in each land-use designation throughout the day 


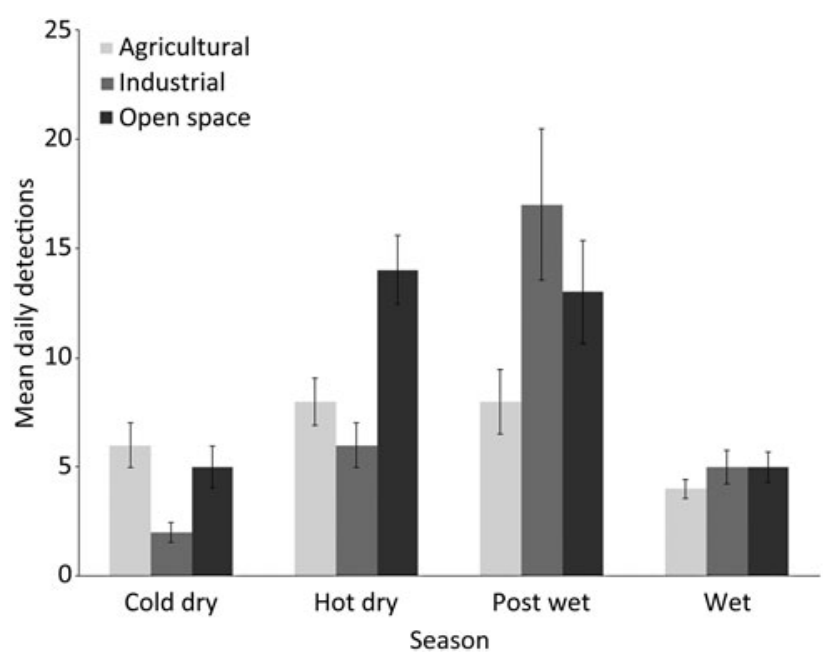

FIG. 2 Mean ( \pm SE) number of elephants Loxodonta africana detected per day in wildlife corridors through agricultural, industrial, and open land in the townships of Kasane and Kazungula (Fig. 1), in the cold dry, hot dry, post wet and wet seasons.

and night, with a diel pattern of use (Fig. 3). Hour, season and land-use designation influenced elephant presence in all corridors (Table 2). More elephants were observed in the evening (Fig. 3; Table 2, Supplementary Table S2), and activity in the corridors was significantly higher at night (18.00-06.0o) than during the day (06.00-18.00; Table 2). More elephants were observed in the post wet $(z=0.89$, $\mathrm{SE}=0.25, \mathrm{P}<0.001)$ and hot dry $(z=1.34, \mathrm{SE}=0.22$, $\mathrm{P}<0.001)$ seasons than in other seasons.

Movement of collared elephants Each of the two GPS satellite-collared elephants used the camera-monitored corridors during the year of the study. The cow ( $\mathrm{CH} 67)$ moved into the town in the wet and post wet seasons. The bull $(\mathrm{CH} 60)$ came into the town at the end of the hot dry season and stayed until the start of the wet season, and then returned in February, March, May and July. They each passed through different corridors in Kasane and Kazungula, moving at similar speeds, and the cow used the corridors more frequently (Table 3 ).

\section{Discussion}

Elephants used the monitored corridors throughout the year, showing temporal patterns of use on both hourly and seasonal scales. Land-use designation did not strongly influence elephants' daily use of the corridors but it influenced their hourly usage. This finding complements the results of Douglas-Hamilton et al. (2005) and Graham et al. (2009), who reported that elephants moved through unprotected areas more quickly and spent less time in those areas, suggesting they were actively managing the amount of time they spent in unprotected areas (Graham et al., 2009).

Our camera trap photographs showed that both bulls and family units with small calves used the urban corridors, whereas previous research has shown females and calves avoiding community areas (Von Gerhardt et al., 2014). The collared cow, a member of a family unit, used the corridors more frequently than the collared bull, and moved through them more slowly, on average. Corridor width was not shown to have a significant effect on elephant presence; however, the shape of a corridor could potentially impede or impact its use by elephants and thus could play an important role in determining the corridor's success. On average, the lowest number of elephants was detected in corridor $\mathrm{B} 1$, a long and narrow fenced pathway that passes through the corridor to the river.

Seasons were shown to affect the temporal patterns of urban corridor use by elephants. The mean daily usage reached a peak in the post wet season, coinciding with the peak of the Chobe River flood. The elephants may have been browsing on the available vegetation before the start of the dry season. Corridor use was also high during the hot dry season, possibly because the elephants needed to access the river more often to stay hydrated.

Rainfall was a significant factor in the daily usage model, with reduced elephant presence in the corridors during the wet season. Rainfall is linked to increased availability of food and water resources in the national park and forestry reserves, and feeds water into natural pans, thus reducing the need for elephants to use the corridors to access the river (Birkett et al., 2012).

Elephants' hourly usage of the corridors followed a diel pattern, with increased elephant presence at night, when elephants are less likely to come into contact with people. This behaviour is consistent with previous studies of elephant occupation of community areas (Sitati et al., 2003; Graham et al., 2009; Songhurst \& Coulson, 2014).

Vehicular traffic in the corridors was used as a variable to measure the impact of human activity on elephant presence. We found opposing trends in road use and elephant presence in each of the land-use designations: traffic density was higher between sunrise and sunset, and elephant presence was higher between sunset and sunrise. However, the rate of traffic did not have a significant impact on elephant presence in any of the corridors. Previous studies found that the construction of roads acted as a barrier to the movement of forest elephants in both protected and unprotected areas (Blake et al., 2008), and that elephants avoided segments of a road passing through a protected area, where there was a higher density of vehicular traffic. We observed the opposite, in that elephants readily crossed the highway to reach the river, although they tended to use the corridors in the evening, when there was less traffic.

It has been suggested that the only way to know if a corridor is functional is to block it and see what happens (Mann \& 


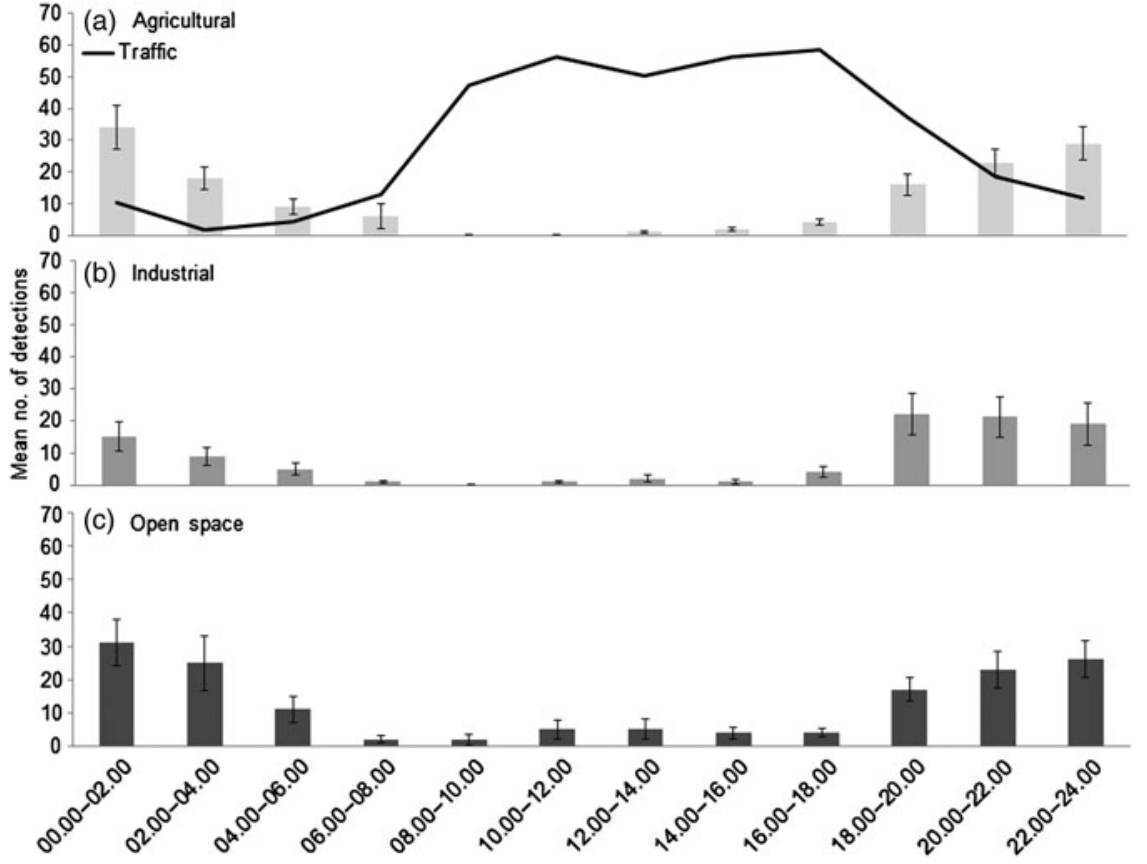

FIG. 3 Mean $( \pm$ SE) number of elephant detections in wildlife corridors through (a) agricultural, (b) industrial, and (c) open land in the townships of Kasane and Kazungula (Fig. 1) during 2-hourly intervals, with mean vehicle density (a), based on recording the number of vehicles using the corridors during a randomly selected 10-minute slot each hour.
TABLE 3 The mean, maximum and minimum speeds at which two elephants fitted with GPS satellite collars passed through urban wildlife corridors in the townships of Kasane and Kazungula, in north-eastern Botswana (Fig. 1), and the number of visits by each elephant.

\begin{tabular}{lll}
\hline & $\begin{array}{l}\text { CH 67 } \\
\text { (mature cow) }\end{array}$ & $\begin{array}{l}\text { CH 60 } \\
\text { (mature bull) }\end{array}$ \\
\hline Mean speed $\left(\mathrm{km} \mathrm{h}^{-1}\right)$ & $0.54 \pm$ SE 0.06 & $0.50 \pm$ SE 0.18 \\
Max. speed $\left(\mathrm{km} \mathrm{h}^{-1}\right)$ & 1.66 & 1.43 \\
Min. speed $\left(\mathrm{km} \mathrm{h}^{-1}\right)$ & 0.07 & 0.01 \\
No. of visits & 27 & 7 \\
\hline
\end{tabular}

Plummer, 1995). Prior to this study a fence was erected by the Seboba Recreational Park across the open space where corridors A1 and A2 were created (Fig. 1). Elephants were unable to gain access to the river and caused damage to the fence, knocking down parts of it (Supplementary Plate S2). The corridors were then established so the elephants could pass through the fence unimpeded, and they caused no further damage. This example highlights the importance of urban corridors in minimizing conflict between people and elephants.

Developing countries balance their development goals with their wildlife conservation objectives (Johnsingh \& Williams, 1999). It is vital for Botswana to implement appropriate management strategies, such as urban corridors, to maintain and preserve Africa's largest remaining elephant population as urban development proceeds. Our results show the functionality of urban corridors in facilitating the passage of elephants through community areas, and it is possible that such corridors could also be used by other wildlife species. The results have been incorporated in the wildlife management plan for the Seboba Recreational
Park, to facilitate the passage of elephants through the Park. Formal protection and designation of urban corridors by the relevant governing bodies would facilitate coexistence between people and wildlife at small spatial scales.

\section{Acknowledgements}

We thank Elephants Without Borders for allowing the research to be conducted under their research permit in Botswana, and the Paul G. Allen Family Foundation and C. Bargmann for financial assistance. The research has been approved by the Botswana Government under the research permit EWT 8/36/4 XX (34), granted by the Department of Wildlife and National Parks to Elephants Without Borders. We thank M. Scott, R. Sutcliffe, J. Halstead and M. Portek for their assistance in the field and with data input; S. McLeod, J. Smith, R. Hartley and S. Brodie for their assistance with statistics; and R. Palmer and D. Clarkson for their assistance with editing.

\section{References}

Birkett, P.J., Vanak, A.T., Muggeo, V.M.R., Ferreira, S.M. \& SLOTOW, R. (2012) Animal perception of seasonal thresholds: changes in elephant movement in relation to rainfall patterns. PLoS ONE, 7(6), e 38363 .

Blake, S., Deem, S.L., Strindberg, S., Maisels, F., Momont, L., IsiA, I.-B. et al. (2008) Roadless wilderness area determines forest elephant movements in the Congo Basin. PLoS ONE, 3(10), e3546.

Brenner, N. \& Schmid, C. (2014) The 'Urban Age' in question. International Journal of Urban and Regional Research, 38, 731-755. Burnham, K.P., Anderson, D.R. \& Hayvaert, K.P. (2011) AIC model selection and multimodel inference in behavioral ecology: 
some background, observations, and comparisons. Behavioral Ecology and. Sociobiology. 65, 23-35.

Caro, T., Jones, T. \& Davenport, T.R.B. (2009) Realities of documenting wildlife corridors in tropical countries. Biological Conservation, 142, 2807-2811.

Carter, N.H., Shrestha, B.K., Karki, J.B., Pradhan, N.M.B. \& LiU, J. (2012) Coexistence between wildlife and humans at fine spatial scales. PNAS, 109, 15360-15365.

Census Office (2014) 2011 Population \& Housing Census Preliminary Results Brief. Central Statistics Office, Gaborone, Botswana.

ChASE, M. (2007) Home ranges, transboundary movements and harvest of elephants in northern Botswana and factors affecting elephant distributions and abundance in the Lower Kwando River Basin. $\mathrm{PhD}$ thesis. University of Massachusetts, Amherst, USA.

Chase, M., Schlossberg, S., Landen, K., Sutcliffe, R., Seonyatseng, E., Keitsile, A. \& Flyman, M. (2015) Dry Season Aerial Survey of Elephants and Wildlife in Northern Botswana: July-October 2014. The Great Elephant Census, Kasane, Botswana.

CLARK, H. (2013) Seasonal movement patterns and home ranges of elephants in northern Botswana. MSc thesis. University of Leeds, Leeds, UK.

Douglas-Hamilton, I., Krink, T. \& Vollrath, F. (2005) Movements and corridors of African elephants in relation to protected areas. Naturwissenschaften, 92, 158-163.

Gilbert, F., Gonzelez, A. \& Evans-Freke, I. (1998) Corridors maintain species richness in the fragmented landscapes of a microecosystem. Proceedings of the Royal Society of London Biological Sciences, 265, 577-582.

Government of Botswana (2012) Aerial Census of Animals in Northern Botswana: Dry Season 2012. Department of Wildlife and National Parks, Gaborone, Botswana.

Government of Botswana (2014) Kasane daily temperature and rainfall report for 2012-2014. Kasane Station. Gaborone, Botswana.

Graham, M.D., Douglas-Hamilton, I., Adams, W.M. \& Lee, P.C. (2009) The movement of African elephants in a human-dominated land-use mosaic. Animal Conservation, 12, 445-455.

Head, J.S., Robbins, M.M., Mundry, R., Makaga, L. \& Boesch, C. (2012) Remote video-camera traps measure habitat use and competitive exclusion among sympatric chimpanzee, gorilla and elephant in Loango National Park, Gabon. Journal of Tropical Ecology, 28, 571-583.

Hilty, J.A. \& Merenlender, A.M. (2004) Use of riparian corridors and vineyards by mammalian predators in northern California. Conservation Biology, 18, 126-135.

Jetz, W., Carbone, C., Fulford, J. \& Brown, J.H. (2004) The scaling of animal space use. Science, 306, 266-268.

Johnsingh, A.J.T. \& Williams, A.C. (1999) Elephant corridors in India: lessons for other elephant range countries. Oryx, 33, 210-214.

Joos-VANDEWALle, S. (2015) The effects of urbanisation on non-timber forest product dependencies: a case study of three settlements in Chobe district of northern Botswana. MSc thesis. University of Cape Town, Rondebosch, South Africa.

Kelt, D.A. \& VAn Vuren, D.H. (2001) The ecology and macroecology of mammalian home range area. The American Naturalist, 157, 637-645.

Kuy kendall, M.T. \& Keller, G.S. (2011) Impacts of roads and corridors on abundance and movement of small mammals on the Llano Estacado of Texas. The Southwestern Naturalist, 56, 9-16.

LaPoint, S., Gallery, P., Wikelski, M. \& Kays, R. (2013) Animal behavior, cost-based corridor models, and real corridors. Landscape Ecology, 28, 1615-1630.

Mangewa, L.J., Kikula, I.S. \& Lyimo, J.G. (2009) Ecological viability of the upper Kitete-Selela wildlife corridor in the Tarangire-
Manyara ecosystem: implications to African elephants and buffalo movements. ICFAI Journal of Environmental Economics, 7, 62-73.

Mann, C.C. \& Plummer, M.L. (1995) Are wildlife corridors the right path? Science, 270, 1428-1430.

Ministry of Lands, Housing and Environment (2000) Scott Wilson Field Investigation, 200o. Department of Town and Regional Planning, Gaborone, Botswana.

Newmark, W.D. (1993) The role and design of wildlife corridors with examples from Tanzania. Ambio, 22, 500-504.

Osborn, F.V. \& Parker, G.E. (2003) Linking two elephant refuges with a corridor in the communal lands of Zimbabwe. African Journal of Ecology, 41, 68-74.

Patterson, B.D. (1984). Mammalian extinctions and biogeography in the Southern Rocky Mountains. In Extinctions (ed. M. Nitecki), pp. 247-293. University of Chicago Press, Chicago, USA.

R Development Core Team (2010) R: A Language and Environment for Statistical Computing. R Foundation for Statistical Computing, Vienna, Austria.

Roever, C.L., van Aarde, R.J. \& Leggett, K. (2013) Functional connectivity within conservation networks: delineating corridors for African elephants. Biological Conservation, 157, 128-135.

Runge, C.A., Martin, T.G., Possingham, H.P., Willis, S.G. \& Fuller, R.A. (2014) Conserving mobile species. Frontiers in Ecology and the Environment, 12, 395-402.

Sitati, N.W., Walpole, M.J., Smith, R.J. \& Leader-Williams, N. (2003) Predicting spatial aspects of human-elephant conflict. Journal of Applied Ecology, 40, 667-677.

Songhurst, A. \& Coulson, T. (2014) Exploring the effects of spatial autocorrelation when identifying key drivers of wildlife crop-raiding. Ecology and Evolution, 4, 582-593.

Songhurst, A., McCulloch, G. \& Coulson, T. (2015) Finding pathways to human-elephant coexistence: a risky business. Oryx, http://dx.doi.org/10.1017/So030605315000344.

Tucker, M.A., Ord, T.J. \& Rogers, T.L. (2014) Evolutionary predictors of mammalian home range size: body mass, diet and the environment. Global Ecology and Biogeography, 23, 1105-1114.

Underwood, A.J. (1997) Experiments in Ecology: Their Logical Design and Interpretation using Analysis of Variance. Cambridge University Press, Cambridge, UK.

Von Gerhardt, K., Van Niekerk, A., Kidd, M., Samways, M. \& HAnks, J. (2014) The role of elephant Loxondonta africana pathways as a spatial variable in crop-raiding location. Oryx, 48, 436-444.

Wright, D.H. \& Coleman, D.C. (1993) Patterns of survival and extinction of nematodes in isolated soil. Oikos, 67, 563-572.

\section{Biographical sketches}

Tempe Adams is devoted to applied conservation research and is focused on the application of scientific theory to facilitate coexistence between people and elephants in Botswana. MICH AE L CH ASE is primarily focused on the status of elephant populations in Botswana and neighbouring countries, and their migratory and cross-border movement behaviour. Tracey Rogers' research aims to understand ecological patterns in mammals, specifically in relation to the ecological and evolutionary consequences of being a certain size, and adopting a foraging or locomotory strategy. KeIth LEGGETT is a spatial ecologist and is primarily interested in movement biology. He worked on the desert elephants in north-west Namibia for many years, where he focused on elephant movement ecology and human-elephant conflict mitigation in arid environments. 